\title{
NOS CONTOS, A NEOLOGIA: INOVAÇÕES LEXICAIS EM "FATALIDADE", DE GUIMARÃES ROSA
}

Jares Gomes Lima*

RESUMO: Neste estudo encontramos usos de derivação prefixal, sufixal e composição na construção de neologismos presentes no conto "Fatalidade", de Guimarães Rosa. Descobrimos dez ocorrências consideradas neológicas e exploramos os processos de formação de cada uma delas. Em relação aos procedimentos metodológicos, atenta-se para: i) levantamento de palavras que possam ser neológicas ainda não prescritas em dicionários socialmente reconhecidos; ii) descrição e classificação dos neologismos e análise do contexto em que se encontra. Como suporte teórico, estudos elaborados por autores como Alves (2004), Kehdi (1992) e Rocha (1998) para definições acerca dos neologismos e estruturas morfológicas do português e, sobre a literatura de Guimarães Rosa, utilizamos Carvalho (1984) e Brait (1982).

PALAVRAS-CHAVE: Léxico; Neologismo; Guimarães Rosa.

\section{Introdução}

Segundo Alves (2004), os neologismos podem ser formados por elementos do próprio sistema linguístico ou por empréstimo de itens lexicais de outro sistema. "Criar novas palavras é apanágio de todo ser humano. Basta que tenhamos um objeto ou um conceito necessitando de rotulação e, neste momento, surge a representação linguística" (MARTINS, 2007, p. 68).

\footnotetext{
* Doutorando em Estudos Linguísticos pela Universidade Federal do Espírito Santo (UFES) e Mestre em Estudos Linguísticos pela mesma instituição. Fez graduação em Letras: Língua Portuguesa e Literaturas de Língua Portuguesa pela Universidade do Estado da Bahia (UNEB). Desenvolve pesquisas com ênfase em Sociolinguística Variacionista, aprofunda-se em temáticas voltadas à variação fonético-fonológica. Atua como pesquisador nos grupos de pesquisa Projeto Português Falado na Cidade de Vitória - PortVix (UFES/CNPq) e Programa de estudos sobre o uso da língua - PEUL (UFRJ/CNPq).
} 
Para Ferraz (2007), através do uso e da frequência com que são usados, os neologismos perdem o sentido de inovação quando se aproximam da memorização no conjunto de unidades lexicais e sua entrada no sistema linguístico se torna efetiva, depois disso ocorre a dicionarização. O uso, então, permite que se torne comum. Dessa maneira, o vocábulo neológico, após a memorização, será incorporado ao léxico da língua.

O conceito de neologismo proposto por Ferraz (2007, p. 55), um conjunto de definições que vão desde o item resultante de uma criação lexical ao resultado tangível de uma produção linguística inédita, aponta o dicionário como um elemento de apoio, já que, em se tratando de uma relação essencial, o diálogo entre neologismo e dicionário permite que uma nova palavra possa ser integrada ao léxico legitimado da língua.

Ferraz (2007) prefere adotar o critério de exclusão lexicográfica, tendo em vista a facilidade na aplicação da metodologia, pois permite maior mobilidade e objetividade na obtenção dos dados. Além disso, a autora recomenda que sejam utilizados dicionários contemporâneos que possuem grande prestígio social, porque neles, teoricamente, estaria previsto o efetivo uso dos falantes em se tratando do léxico do português.

Sabendo disso, consideramos que o uso de dicionários facilita a identificação de neologismos, no entanto, não funciona como aporte seguro para as novas palavras, pois construímos novos vocábulos a todo momento, o que independe de seu registro já que algumas dessas criações são temporárias. Para Basílio (2011), significa que os dicionários estariam defasados em relação às palavras da língua.

Para Rocha (1998, p. 95), para que a entrada da nova palavra seja realizada no dicionário, é necessário que aconteça sua institucionalização, tornar a palavra familiar a um grupo de indivíduos, porque não faria sentido um dicionário registrar formações esporádicas. Para que o neologismo seja integrado como uma unidade lexical comum, é preciso que ele aconteça com certa regularidade no sistema, causando sua desneologização.

Sabendo disso, tentando averiguar algumas ocorrências neológicas no texto literário, estabelecemos alguns objetivos para este trabalho: verificar a existência de neologismos no conto "Fatalidade", do livro Primeiras Histórias, de Guimarães Rosa (2001); refletir sobre 
a escrita inventiva do autor e o que contribui para os sentidos atribuídos aos vocábulos neológicos; perceber como os neologismos são inseridos dentro do conto e quais as classes gramaticais atribuídas a eles; bem como examinar os processos de formação de palavras mais produtivos na construção dos neologismos.

Nesse sentido, em resumo, faremos um levantamento de palavras consideradas neológicas ainda não prescritas em dicionários socialmente reconhecidos; assim como uma descrição e classificação dos neologismos, além da análise do contexto em que se encontra. Certamente, seguiremos as propostas de Ferraz (2007) acerca da exclusão lexicográfica.

Aos vocábulos neológicos são conferidos sentidos que devem ser analisados com maior propriedade visando sua desneologização (ALVES, 2004). Esta pesquisa se justifica por ser um trabalho que extrapola estudos somente literários ou apenas linguísticos em função da mescla realizada pelo próprio Guimarães Rosa para maior expressividade de seu texto (CARDOSO, 2009).

\section{Os neologismos na literatura}

Na produção do texto literário, o autor tem liberdade para criar palavras sem mesmo utilizar os processos de formação comuns na Língua Portuguesa. Quando analisamos os neologismos no texto literário "deve-se tanto lançar mão de uma análise morfológica quanto de uma análise estilística, uma vez que, no discurso literário, são exploradas as potencialidades expressivas das palavras" (IGNEZ, 2009, p. 29).

Assim, diz-se que as criações lexicais literárias ou estilísticas se comportam de maneira diferente das demais criações. Apresentam apenas um valor expressivo naquele momento e naquele texto. Cumprido o seu papel expressivo, tendem ao esquecimento. Motivam-se a cada leitura. Dificilmente passam a integrar o léxico da língua. Entretanto, têm um valor enorme porque vêm mostrar que, além de a criação ter um fundo prático e necessário, ela também pode surgir como um simples valor expressivo, ou lúdico. (CARDOSO, 2008, p. 12)

A escrita literária possui um valor estético próprio e quando aliada à possibilidade de inovação linguística adquire maior status de inovador porque consegue apropriar-se de 
características que permitam à sua própria escritura utilizar o contexto, tanto linguístico quanto social.

Para Nelly Carvalho (1984), a arte elaborada na literatura se renova a partir de novas formas, momento em que podem ser incluídas as novas palavras. A principal característica da criação de palavras no texto literário está ligada ao autor, pois nas escolhas dos vocábulos e na formação deles consegue produzir um estilo que lhe é particular.

Conforme Carvalho,

A linguagem literária, apesar de distanciada da cotidiana, exerce sobre esta enorme influência.

Todas as gramáticas têm sua exemplificação a partir das obras dos autores consagrados, tornando-os como padrão.

O leitor reconhece a autoridade do escritor, nos domínios da linguagem, motivo pelo qual os usos e inovações na literatura são aceitos (CARVALHO, 1984, p. 28)

Há uma valorização da escrita literária por parte dos gramáticos, tornando-a um padrão para escrita. Em razão disso, e em se tratando do domínio do escritor na expressão de seu texto, as inovações na literatura são aceitas. A estética literária pode exercer seu papel de representante da língua, no entanto, ainda continua atrás em se tratando da representação da fala cotidiana. Mesmo assim, não invalida a representação que faz do uso da língua por se tratar de uma modalidade diferente da fala.

Para Cardoso,

[...] pode-se optar entre a subjetividade e a objetividade, entre o discurso direto e o indireto, pode-se escolher formas de tratamento diferentes. Pensando na organização de períodos, pode-se optar entre a subordinação e a coordenação, ou ainda pensando na organização da frase, opta-se pela ordem direta ou inversa etc (CARDOSO, 2004, p. 149)

No caso de Guimarães Rosa, algumas das criações dependem também do conhecimento de arcaísmos, que podem ser usados nos neologismos, chegando a dificultar a leitura. Apesar disso, não nos preocupamos em verificar se eram ou não arcaísmos. Nossos 
critérios valem-se apenas de dicionarização ou não dicionarização dos neologismos encontrados. Acreditamos que seria outro tipo de análise se nos preocupássemos com aspectos históricos envolvidos na formação dessas criações.

Para os arcaísmos, Suassuna (1999) aborda alguns deles presentes em dois textos de Guimarães Rosa, Grande Sertão: veredas e Primeiras Estórias, realiza a análise junto a arcaísmos recuperados de textos do período arcaico da Língua Portuguesa. Entre os arcaísmos encontrados por Suassuna (1999), são apresentados alimpar (limpar), alembrar (lembrar), malino (maligno), meo (meu), entre outros exemplos. Suassuna (1999) também argumenta que essas palavras estão presentes no texto de Guimarães pelo fato de o autor trazer os regionalismos em seus textos, representando uma fala presente no interior das regiões de Minas Gerais e São Paulo, lugares por onde realizava suas andanças como médico.

Para Ignez, “[...] os neologismos em textos literários são importante objeto de estudo, pois, normalmente, dão ao texto um sabor de novidade e expressividade. As criações geram surpresa, bem como podem produzir efeitos humorísticos” (IGNEZ, 2009, p. 33). Certamente, a expressividade transporta ao texto literário as expectativas do autor para adesão ao texto por parte dos leitores, ou simplesmente transferem o que o autor espera do que seja uma boa escrita.

Por meio do que Ignez (2009) aponta, enfatizamos que as criações ocorridas nos textos, mesmo que não estejam no uso efetivo dos falantes, representam as possibilidades de inovações que ocorrem na língua, tendo em vista que são feitas para estabelecerem redes de sentido e alcançarem uma expressividade suficiente na significação dessas inovações, pois, através de um jogo de palavras, servem como aliadas na elaboração do texto literário.

\footnotetext{
A língua é uma grande aliada do enunciador por dar a ele tantas opções. É claro que se pode escolher sempre dentro daquele conjunto de possibilidades; caso contrário, corre-se o risco de se cair na falta de comunicação. É possível, também, alterar esses elementos, criando formas novas que, se compreendidas, podem ser utilizadas (CARDOSO, 2004, p. 150)
}

Entretanto, o jogo de palavras pode não funcionar se utilizado demasiadamente, quando não há nenhuma intenção a ser inserida na tessitura do texto. Neologismos que são 
feitos por processos de formação de palavras previstos na Língua Portuguesa, ou formados por desvios dela, presumivelmente, podem culminar na valorização do autor, desde que haja intenção em sua criação. Sendo assim, mesmo sendo elaborado pelo desvio da língua, o texto pode ser motivador de leitura e o autor valorizado (CARDOSO, 2009).

\section{A literatura de Guimarães Rosa}

Guimarães Rosa tornou-se referência para estudos sobre o léxico. Os seus textos servem como corpora para pesquisas que suscitam análises com predominância em aspectos morfológicos, semânticos e sintáticos, relacionados à gramaticalização, também aos estudos lexicais, e aos estilísticos, além dos estudos no campo da própria literatura. Por se tratar de um texto literário, não devemos deixar de levar em consideração a expressividade que o escritor consegue trazer aos seus textos.

Nelly Carvalho afirma que "na nossa literatura, o maior inovador foi sem dúvida alguma Guimarães Rosa” (CARVALHO, 1984, p. 29). A autora ainda diz que

Guimarães Rosa prima pela criação de neologismos que dão a seu estilo um colorido incomum. Utiliza os mais diferentes processos de formação de palavras com radicais gregos, latinos, indígenas e africanos. Resulta uma linguagem 'viril e pedregosa' no dizer dele mesmo, áspera e por vezes difícil, cujo sentido só se aprende bem após uma segunda leitura (CARVALHO, 1984, p. 29)

Os usos dos neologismos são marcas bem definidas nos textos de Guimarães Rosa, e, como dito antes, são abordados diversos aspectos para a formação das palavras em suas produções. Conforme Carvalho (1984), o escritor possui uma linguagem forte, somente pode-se compreender bem os sentidos após uma segunda leitura. Trata-se de uma linguagem que nos chama atenção, no que diz respeito aos aspectos expressivos, como também se torna uma leitura difícil no momento em que a linguagem passa a ser pedregosa (CARVALHO, 1984) em virtude do uso de termos que advinham do seu largo conhecimento da Língua Portuguesa e de outras línguas as quais aprendeu.

Conforme Beth Brait (1982), o regionalismo talvez seja a principal marca nos contos e romances de Rosa. Funcionando como um elo 
entre o real e o mágico, de forma a radicalizar os processos mentais e verbais inerentes ao contexto fornecedor de matéria-prima. $\mathrm{O}$ folclórico, o pitoresco e o documental cedem lugar a uma maneira nova de repensar as dimensões da cultura, flagrada em suas articulações no mundo da linguagem (BRAIT, 1982, p. 102)

Na década de 40, com Clarice Lispector, e nos anos 50, com João Guimarães, a literatura brasileira encontra novas maneiras de expressão e que são peculiares a cada autor (CARVALHO, 1984). Para Brait (1982) é muito difícil conseguir copiá-los visto que seus estilos são muito particulares, tão especiais que não se pode racionalizar e apropriarem-se do estilo de transmissão da mensagem.

Em Guimarães Rosa, percebemos traços de uma linguagem característica do sertão brasileiro. No conto analisado neste artigo, "Fatalidade", tem-se a presença de personagens que evidenciam este contexto.

O conto é narrado em terceira pessoa e a maioria dos neologismos é produzida pelo narrador, apesar de inseridas algumas falas das personagens no conto. Há um delegado que conduz a cidade, chamado no conto de Meu Amigo, simbolizando o comando de tudo. Em José de Tal, apelidado de Zé Centeralfe, um dos personagens principais, percebe-se o apelo que o escritor dá aos moradores do sertão, pessoas pobres que dependem dos grandes donos de terra. O cenário é descrito como uma cidade pobre, as pessoas de maior poder aquisitivo são aquelas que influenciam o cotidiano da cidade.

Portanto, com uma linguagem característica do sertão, que foi construída com extrema maestria, assim como a temática e a presença de personagens bem marcantes, João Guimarães Rosa elabora um texto que delineia um alvo na descoberta de caminhos possíveis para a construção do texto literário.

\section{Os neologismos no conto "Fatalidade"}

Nos atentamos à retirada e análise de neologismos no conto "Fatalidade". Em sua narrativa, a estória de um homem, que apareceu na cidade há pouco tempo, apelidado de Zé Centeralfe, é apresentada. 
Depois de acomodar-se no arraial, Zé Centeralfe pede ajuda a um dos manda-chuva, o delegado nomeado de Meu Amigo. A estória descreve uma perseguição sofrida por Zé pelo valentão Herculinão Socó. Zé Centeralfe veio fugido da cidade de Pai-do-padre para o arraial de Amparo, por causa da cisma do valentão com a esposa dele. O delegado toma para si a inquietação do pequeno homem e resolve procurar o valentão.

Durante a estória, Centeralfe conta sua situação para o delegado. Por existir no arraial alguém representando uma ameaça ao seu comando, Meu Amigo acolhe Centeralfe e seu suplício, culminando em um posterior duelo com Herculinão. Conforme a característica de fatalista e de boa mira, o delegado mata Herculinão com um tiro certeiro. A estória termina com o enterro do valentão "para a sua competente cova" (ROSA, 2001, p. 112).

Depois das leituras do conto e análise dos prováveis neologismos, passamos à identificação dos vocábulos neológicos. Utilizamos o método proposto por Ferraz (2007), a exclusão lexicográfica, que consiste na consulta das palavras aos dicionários mais veiculados a fim de verificarmos se estão dicionarizadas. Valemo-nos de três dicionários, a saber: Novo dicionário da Língua Portuguesa, de Aurélio Buarque de Holanda (FERREIRA, 1986), o Michaelis: moderno dicionário da língua portuguesa (WEISZFLÖG, 1998) e o Dicionário Houaiss de Lingua Portuguesa, organizado por Antônio Houaiss, Mauro Villar e Francisco Franco (HOUAISS; VILLAR; FRANCO, 2001).

Também utilizamos o texto de Martins (2001), uma obra em forma de dicionário que traz a localização e explicações de características dos vocábulos, seus empregos e fundamentos linguísticos, bem como uma eventual criação vocabular, um guia básico para auxílio e avanço dos leitores na leitura do texto roseano. Isso torna a obra de Martins (2001) um dos critérios para selecionarmos e considerarmos como novas palavras aquelas que também não constariam na reunião realizada pela autora.

Os dicionários foram escolhidos por sua grande circulação e valorização no Brasil, além de terem sido elaborados por grandes dicionaristas. Optou-se pela verificação de dicionários mais recentes, pois a primeira edição do texto analisado foi publicada em 1962. 
Sendo assim, caso as palavras tenham sido dicionarizadas, não iriam para análise. A desneologização dos vocábulos é configurada no momento em que são dicionarizados, tendo em vista que os dicionários registram o efetivo uso dos falantes ou a existência dele. Depois de feita a identificação, nos voltamos para a análise da formação de palavras, às configurações morfológicas dos neologismos.

Seguimos o que Kehdi (1992) aponta para os conceitos acerca de derivação e composição porque nos parecem mais simples facilitando nossa compreensão acerca dos processos de formação de palavras. O autor nos diz que derivação é "quando um vocábulo é formado de um só radical, a que se anexam afixos” (KEHDI, 1992, p. 7) e a composição acontece "quando dois ou mais radicais se combinam" (KEHDI, 1992, p. 7). Para os exemplos de derivação, temos:

(01) $\quad \operatorname{reter}(=$ re (pref. $)+$ ter $)$

(02) cordialmente $(=$ cordial + mente (suf.) $)$

Para a composição:

(03) guarda-roupa

(04) couve-flor

$\mathrm{Na}$ apresentação dos resultados não faremos descrições precisas entre as composições por aglutinação e justaposição, pois é um processo em que se juntam duas bases preexistentes para criar um novo vocábulo, dito composto (ROCHA, 2003, p. 187). Exploraremos com mais vigor os processos de derivação por serem mais frequentes nos neologismos encontrados em Guimarães Rosa (2001).

Começaremos pela derivação prefixal. Segundo Rocha (2003, p. 151), é um processo que incide na formação de uma palavra por meio do acréscimo de um prefixo a uma base já existente. O prefixo é colocado à esquerda de uma base para que a nova palavra seja formada e se caracteriza pelo fato de ser uma forma presa (ROCHA, 2003, p. 151).

Kehdi (1992) nos lembra que alguns prefixos podem ser autônomos, nos casos de preposições, contra e entre, e nos alerta que isso só se aplica a alguns prefixos, pois outros somente aparecem como formas presas, casos como desigual e rever. O mesmo aconteceria 
para os sufixos que podem também ser autônomos e formas presas, como mente "espírito" e rapidamente, recentemente, de modo respectivo. O que nos leva a considerar tanto a prefixação e sufixação como casos de derivação (KEHDI, 1992, p. 8). No entanto, para que exista uma derivação, é necessária a presença de apenas uma raiz (ROCHA, 2003).

Em relação à derivação parassintética, Rocha (2003) e Basílio (2011) afirmam que acontece quando há o acréscimo simultâneo de um prefixo e sufixo a uma base. Basílio (2011) acrescenta que o prefixo especifica uma alteração semântica e o sufixo especifica a categoria da palavra resultante. A exclusão de um dos afixos implicaria a inexistência da palavra na língua (BASÍLIO, 2011; KEHDI, 1992). Ambos os afixos são acrescentados ao mesmo tempo à base constituindo um único morfema gramatical (SILVA \& KOCH, 2011, p. 53). Quanto às divergências relacionadas aos conceitos de parassíntese, não serão aproveitadas neste trabalho.

Por fim, a respeito da parassíntese, pode-se afirmar que sua base será sempre nominal, substantiva ou adjetiva. Há um número maior de formações com base substantiva do que adjetiva e seus produtos serão sempre verbos e adjetivos. Além disso, existem mais formações parassintéticas verbais do que adjetivais e a regra mais comum na parassíntese é um verbo a ser originado de uma base substantiva (ROCHA, 2003, p. 170).

Para os episódios de derivação, na análise, seguiremos a proposta de Kehdi (1992). Os casos nos quais parecem apresentar uma estrutura mais complexa, como revezadamente, por exemplo, serão melhor resolvidos por meio de uma análise que utiliza os constituintes imediatos (C.I.), quando vistos a partir de superposições binárias.

Identificamos no conto 10 novas palavras. Dentre elas, encontramos 3 formadas por composição, 6 formadas por derivação sufixal e 1 formada por derivação prefixal, apresentadas no Quadro 1. 
Quadro 1: Palavras encontradas no conto não dicionarizadas

\begin{tabular}{|c|c|c|c|}
\hline \multicolumn{4}{|c|}{ PALAVRAS IDENTIFICADAS COMO NEOLOGISMOS } \\
\hline \multirow{11}{*}{$\begin{array}{c}\text { PROCESSOS DE } \\
\text { FORMAÇÃO DE } \\
\text { PALAVRAS }\end{array}$} & \multirow{4}{*}{ COMPOSIÇÃO } & VOCÁBULO & CATEGORIA \\
\hline & & vinte-e-muitos & numeral \\
\hline & & rabo-do-olho & Substantivo \\
\hline & & cujalma & Adjetivo \\
\hline & \multirow{6}{*}{$\begin{array}{c}\text { DERIVAÇÃO } \\
\text { SUFIXAL }\end{array}$} & fabulável & Adjetivo \\
\hline & & revezadamente & Advérbio \\
\hline & & nominoso & Adjetivo \\
\hline & & biograficamente & Advérbio \\
\hline & & causavelmente & Advérbio \\
\hline & & descompassante & Adjetivo \\
\hline & $\begin{array}{l}\text { DERIVAÇÃO } \\
\text { PREFIXAL }\end{array}$ & reespiritado & Adjetivo \\
\hline
\end{tabular}

Fonte: o autor

A partir deste momento abordaremos os neologismos encontrados no conto e analisaremos a partir do trecho em que aparecem no conto, principalmente, aquelas com o processo de formação mais usado, a derivação sufixal, e o mais comum a ser produzido na Língua Portuguesa.

O primeiro é o vocábulo fabulável (ROSA, 2001, p. 108). Este neologismo é um adjetivo formado a partir de derivação sufixal. O sufixo (á)vel indica que há possibilidade de o sujeito em questão sofrer ou praticar uma ação. O sufixo está ligado ao verbo fabular, visto que, no sentido empregado no contexto "Ponto é que Meu amigo existia, muito; não se fornecia somente figura fabulável, entenda-se" (ROSA, 2001, p. 108, grifo nosso), temse no delegado, Meu Amigo, a pessoa que poderia ser fabulada, pois há possibilidade de ser construída uma figura ainda mais fictícia devido às características muito boas e justas presentes nela.

Destacando os morfemas constitutivos do vocábulo fabulável, percebemos que a partir da comparação fábula - fabulável é permitido depreender que no sufixo -ável, que pode aparecer como -ivel e -úvel, precisa ser destacada a vogal temática - $a$. Kehdi (1999, p. 
34-35) classifica em vogais temáticas nominais e verbais e , neste caso, por considerarmos o verbo latino fari, que significa "o que é falado antes", como uma provável etimologia para a palavra fábula, tratamos como uma vogal temática verbal, além, é claro, de considerarmos o verbo fabular como uma das bases para a formação do neologismo em questão.

Temos também outro adjetivo, nominoso (ROSA, 2001, p. 110). Para esse neologismo, Azevedo (2018, p. 376) considera que seja de origem grega, uma tradução de daimonion, que passa pela palavra correlata latina de tradução usual numinoso. Porém, em nota de rodapé, Azevedo (2018) diz que também pode ser um caso de derivação e/ou possuir origens diversas do adjetivo latino e não grego. Em Azevedo (2018), há uma excelente leitura e análise do conto "Fatalidade", numa relação que o autor estabelece em referências implícitas e explícitas à cultura grega.

No presente trabalho consideramos que nominoso é um neologismo criado por meio do processo de derivação sufixal, um substantivo foi ligado ao sufixo formador de adjetivos -oso. O neologismo serve como um outro nome para o valentão Herculinão. Quando o vocábulo neológico aparece no texto, o narrador conta a situação de Zé Centeralfe, que teve de sair da cidade em que estava por causa da perseguição sofrida. "Mas, o homem, o nominoso, não tardou em aparecer” (ROSA, 2001, p. 110, grifo nosso).

No trecho em análise, percebemos a característica de adjetivo, pois a personagem é considerada como aquele que possui um grande nome, porém com uma carga bastante negativa. Segundo Martins (2001, p. 354), um sujeito nefasto e execrável e que talvez possuísse bastante influência no local, até em outros lugares. Devemos enxergá-lo também como um novo substantivo para a personagem Herculinão, chegando a substituir o nome pelas qualidades que a personagem apresenta.

Para o sufixo -oso, Sandmann (1987, p. 63) considera que seja bem menos produtivo hoje do que foi no latim e em outras fases do português, como exemplo, utiliza o caso de formosu, preguiçoso em português. No entanto, a partir de sua observação na fala dos mais jovens, pondera que esteja ganhando um rejuvenescimento em sua produtividade. 
Basílio (2011) nos lembra que o sufixo acrescenta aspectos semânticos à base substantiva e nos permite entendê-lo como algo "provido de". A autora sustenta nossa análise e corrobora ideia apontada por Martins (2001), caracterizando a personagem Herculinão como aquele que é provido de qualidades e influências negativas.

Em se tratando da palavra revezadamente (ROSA, 2001, p. 107), é um vocábulo que mesmo não tendo sido dicionarizado foi mencionado no dicionário Aurélio, porém não aparece como verbete. Apenas consideramos o vocábulo como neologismo porque nos demais dicionários esta unidade linguística não aparece, assim como não aparece na reunião realizada por Martins (2001).

O neologismo é formado por derivação sufixal, o sufixo -mente é utilizado para a formação de um advérbio, um processo bastante produtivo na língua. Ao invés de uma base adjetiva, mais comum na Língua Portuguesa, temos uma categoria de base formada por um particípio. Segundo Cavalcante (1996, p. 57), os particípios também são bases lexemáticas que podem admitir o sufixo -mente. No entanto, o autor menciona que são bases mais resistentes ao processo de derivação em -mente do que os adjetivos, há uma certa dificuldade em elaborar regras para dar conta desse tipo de derivação.

Mesmo havendo, estruturalmente, uma maior dificuldade para a ocorrência de neologismos em -mente com particípio, Rosa (2001) consegue apropriar-se da alta produtividade do sufixo com adjetivos e atribui ao particípio com valor de adjetivo uma produção que consideramos ser altamente aceitável. No trecho "Na data e hora, estava-se em seu fundo de quintal, exercitando ao alvo, com carabinas e revólveres, revezadamente" (ROSA, 2001, p. 107, grifo nosso), percebemos o sentido atribuído ao advérbio, na alternância feita entre os tipos de armas de fogo realizada pela personagem Meu Amigo, o que corrobora nossa proposta de que Rosa (2001) consegue atribuir um sentido sem a perda de propriedades semânticas da base de cunho adjetivo em que o neologismo é elaborado.

Nos casos de biograficamente e causavelmente, seguindo nossa ideia de alta produtividade do sufixo na Língua Portuguesa, temos dois advérbios elaborados a partir de bases nominais adjetivas. Esses neologismos aparecem nos trechos: "Meu Amigo o interrompeu; 
ele seguia biograficamente os valentões do Sul do Estado" (ROSA, 2001, p. 109, grifo nosso); e "Meu amigo, tão valedor, causavelmente, de vá-à-garra o deixava?" (ROSA, 2001, p. 111, grifo nosso). Trataremos os neologismos juntos, biografica+mente e causavel+mente, utilizando uma análise de C.I, em camadas binárias de superposição. Há dois adjetivos junto ao sufixo formador de advérbios.

Para causavelmente, trazemos o que Cavalcante (1996, p. 56) considera em relação aos nomes adjetivos atemáticos que terminam em -1, -m, -s, -z. Cavalcante (1996) argumenta que podem ser formados itens lexicais a partir desses adjetivos. Nesses casos o sufixo mente é ligado a uma base atemática, exemplificando a ocorrência com as palavras notavelmente, comumente, simplesmente e velozmente.

Kehdi (1999, p. 38) diz que as consoantes de ligação mais produtivas são / z/ e /1/, sendo raras as ocorrências com outras consoantes, o que nos parece ser aceitável, se olharmos para a maior frequência de palavras terminadas com essas duas consoantes. Ainda podemos depreender mais um constituinte do neologismo, o sufixo -vel, formador de adjetivos, já discutido antes, do vocábulo -causa. O que não afetaria nossa análise, pois a formação de advérbios em -mente continua a partir de uma base nominal.

Já em biograficamente, há a presença de uma vogal temática, além de uma vogal que liga a base adjetiva ao sufixo. Temos uma base terminada em /-u/ com o acréscimo de uma vogal de ligação, há elisão do -o, presente no adjetivo de base, pelo -a. A adição do sufixo -mente é realizada pela vogal de ligação à base temática.

Consideramos interessante o uso do neologismo descompassante, criado também por meio do processo de derivação sufixal. Defendemos que seja um processo de sufixação, pois para que o sentido seja atribuído totalmente devemos perceber apenas o sufixo ligado a uma base substantiva. Temos um adjetivo terminado em -nte. Como bem nos lembra Basílio (2011), os sufixos determinam a categoria. Como estamos verificando o uso de sufixação, decomporíamos o neologismo como descompasso $+a+$ te (base + vogal de ligação+sufixo) $=$ descompassante. 
Não consideramos a ideia de que seja um processo parassintético, tendo em vista que não há possibilidade de dois afixos serem anexados ao mesmo tempo. Se o fizéssemos, apenas uma construção seria agramatical, * compassante. E se retirássemos apenas o sufixo, teríamos uma palavra já existente na língua, descompasso. Seguindo nosso critério de análise binária, apenas destacamos o constituinte -nte, sufixo formador de adjetivos. Além disso, também poderíamos destacar um outro constituinte, o prefixo -des, da base -compasso. No texto, o neologismo aparece no trecho " $\mathrm{E}$ - de repente e súbito - precipitou-se a ocasião: lá vinha, fatalmente, o outro, o Herculinão, descompassante” (ROSA, 2001, p. 111, grifo nosso), o que fortalece nossa análise de derivação sufixal que forma um adjetivo.

Encontramos apenas um caso de derivação prefixal na formação dos neologismos presentes no conto. A palavra formada a partir da prefixação é reespiritado. Decompondo em dois constituintes, teríamos um prefixo -re ligado à base adjetiva, um particípio, -espiritado. Rocha (2003, p. 164) afirma que -re é um prefixo homófono, pois apresenta mais de uma significação para uma mesma sequência fonológica. O autor mostra três significações para o prefixo: a ideia de repetição; de movimento para trás; e o sentido de movimento contrário.

No conto, o neologismo aparece no seguinte trecho: "Sem mais perplexidades, se ia. Agradecia, reespiritado, com sua força de seu santo” (ROSA, 2001, p. 111, grifo nosso). Percebemos que a ideia de repetição pode ser atribuída, já que Zé Centeralfe, depois da conversa com Meu Amigo, volta com as forças de seu interior renovadas pela esperança que o delegado proporciona. A facilidade na segmentação em apenas dois constituintes revela com melhor acuidade o sentido conferido ao neologismo. O fato de a base -espiritado já ser dicionarizada nos permite também esta decomposição binária, também para atribuirmos um sentido ao uso do neologismo no texto roseano.

Para os casos de composição, veremos com mais detalhes o neologismo cujalma. O vocábulo aparece no trecho “Por conta daquele. - 'Cujalma!' - proferiu Meu Amigo, meticuloso indo ajeitar uma carabina, que se exibia, oblíqua, na parede" (ROSA, 2001, p. 110, grifo nosso). Para esse neologismo, Azevedo (2018, p. 377) menciona, em nota, que acentua 
o péssimo caráter da personagem Herculinão. Para Azevedo (2018) realça o caráter diabólico da personagem, pois se refere à alma do próprio cujo, do demo. Dito-cujo é uma palavra relativamente usada no interior de alguns estados brasileiros para se referir a alguém que não se quer falar o nome ou não se sabe. Esta também pode ser uma referência. Parecenos que Cujalma deve ser encarada como um xingamento que Meu Amigo faz a Herculinão.

Decompondo em dois constituintes, teríamos cujo(a)+alma, são duas bases já existentes que foram combinadas. Segundo Kehdi (1992), a composição "é um processo de formação lexical que consiste na criação de palavras novas pela combinação de vocábulos já existentes: amor-próprio; ganha-pão” (KEHDI, 1992, p. 35). E assinala que, na palavra composta, os elementos que a compõem perdem a significação própria em razão de um único conceito (KEHDI, 1992).

Ainda conforme Kehdi (1992), na composição, a ordem dos termos é rígida e não se pode inserir outro elemento, eles não podem ser substituídos ou suprimidos. Além disso, podem apresentar construções sintáticas anômalas e funcionam sintaticamente como uma única palavra. Quanto à estrutura dos compostos, é bastante variada. No caso em análise, há um pronome + substantivo: cujo + alma, que foram aglutinados, com perda de massa fônica de um dos constituintes, há a elisão de uma desinência.

Acreditamos que nos neologismos formados por composição existe uma influência maior de palavras presentes em regiões interioranas. Como no caso do neologismo, rabodo-olho, encontrado no trecho "Meu Amigo, mandando-lhe sentar e esperar, continuou, baixo, a conversa; fio que, apenas, para poder melhor observar o outro, vez a vez, com o rabo-do-olho, aprontando-lhe a avaliação" (ROSA, 2001, p. 108, grifo nosso). Apesar de não ter sido dicionarizado, já observamos a ocorrência desta mesma palavra em nossa cidade natal. Considerando que seja uma variação do neologismo, a palavra rabo-de-olho é comum em algumas cidades do interior da Bahia.

O sentido empregado também é bastante parecido com o que observamos em ocorrências na Bahia. Nossa proposta é que o sentido seja advertir com um olhar crítico. Pode indicar julgamento e avaliação e/ou reprovação, o mesmo sentido atribuído às ocorrências 
na fala. O critério que utilizamos para considerar uma palavra como neologismo é o dicionário. Dessa maneira, ainda consideramos como um novo vocábulo, porém está implementado na fala, a partir da observação participante, e não foi dicionarizado.

O neologismo é formado pela composição por justaposição, "quando os termos associados conservam a sua individualidade" (KEHDI, 1992, p. 36). Tal fato corrobora nossa hipótese de que os neologismos formados por composição possuem maior influência da fala de pessoas das regiões nas quais Guimarães Rosa tenha passado.

O mesmo acontece para o neologismo vinte-e-muitos. Na fala, temos ocorrências como vinte-e-tantos, ou vinte-e-uns. Todos os usos estão se referindo às idades de alguém no momento da fala, até mesmo do próprio falante. No conto, aparece em "O qual, vendo-se que caipira, ar e traje. Dava-se de entre vinte-e-muitos e trinta anos; devia ter bem menos, portanto" (ROSA, 2001, p. 108, grifo nosso). Acreditamos que o neologismo indica um intervalo entre faixas etárias, o vocábulo nomeia o espaço que presumivelmente estaria entre 20 e 30 anos.

Novamente temos um caso de composição por justaposição, que confere aos constituintes perda de carga semântica no momento da criação do novo vocábulo. Não se sabia ao certo precisar a idade do Zé, o narrador utiliza algo que pressupõe uma faixa etária. Observamos que o sentido pode ser o mesmo nas ocorrências percebidas na fala por observação participante.

O fato de a composição ser um processo aparentemente mais simples, porque preserva a individualidade das palavras, facilita sua entrada no acervo lexical. Mesmo que Guimarães Rosa tenha sido reconhecido por sua inventividade, o autor parece utilizar também palavras que já apareciam no uso das pessoas de sua época. Isso confere a ele uma maior notoriedade porque realmente tenta construir sua literatura como uma representação social. 


\section{Considerações finais}

A obra de Guimarães Rosa permite tanto abordagens ligadas à literatura quanto esta ligada aos estudos linguísticos, possibilitando discussões que sirvam para análises aprofundadas sobre as construções do escritor. Empreendemos uma reflexão sobre sua escrita inventiva e percebemos como ele utiliza as possibilidades de construção de palavras presentes na Língua Portuguesa para obter uma expressividade única em suas invenções linguísticas. Os aspectos regionalistas são muitos fortes e estabeleceram uma das características mais observadas nos textos. Nossos resultados indicaram que algumas influências regionais não estão relacionadas apenas à linguagem e escolhas lexicais, mas na construção delas.

Suas inovações não fogem aos detalhes regionais presentes no uso das palavras. Mesmo que na literatura roseana suas inovações estejam no texto escrito, alguns neologismos encontrados ainda são utilizados na fala. As palavras formadas por composição são um excelente ponto de discussão. Rosa (2001) apropria-se do vocabulário local e constrói seu texto para trazer uma expressividade única.

Sob nossa ótica, processos que não preservem propriedades semânticas dos constituintes presentes nas criações são preferidos pelo autor pelo fato de trazer in natura a linguagem interiorana, pois na composição o autor trouxe neologismos muito próximos às ocorrências na fala, bem como a frequência superior de adjetivos ser um índice para maior produtividade de neologismos desta categoria também na fala.

Nossos resultados corroboram ideia de apego do autor pela representação da fala, ou uma pista para isso, por encontrarmos palavras que ainda hoje são utilizadas, algumas delas registradas efetivamente pelo autor na década de 60 . Os regionalismos são realmente um ótimo ponto de pesquisa, no entanto, nossa proposta era verificar os processos de formação de palavras utilizados por Rosa para construir os neologismos e coletar as palavras que ainda não haviam sido dicionarizadas.

Os 10 vocábulos neológicos retirados do conto provaram que a derivação sufixal é o processo mais utilizado por Rosa. Quanto às categorias, foram formados principalmente adjetivos, 5 deles, seguidos de 3 advérbios, 1 substantivo e 1 numeral. 
Nossas análises empreenderam tanto uma análise linguística quanto literária para a verificação das ocorrências neológicas e os sentidos foram atribuídos também por causa dos processos de formação de palavras envolvidos.

\title{
IN THE TALES, NEOLOGY: LEXICAL INNOVATIONS IN FATALIDADE BY GUIMARÃES ROSA
}

\begin{abstract}
This paper verifies the neologisms found in the story Fatalidade, from the book Primeiras Histórias, by Guimarães Rosa. Our proposal consists of the survey probable neological occurrences verifying the occurrence or not on the dictionary. We point out the use of prefixal, suffixal and composite processes in words considered neological. We found ten neologisms will be explored. With regard to methodological procedures, this study is concerned with: i) raising words that may be neological creations not yet prescribed in socially recognized dictionaries; ii) description and classification of neologisms and analysis of the context in which it is found. The study is based on the postulates of Alves (2004), about neologisms; Kehdi (1992) and Rocha (1998) for concepts about the morphological structures of Portuguese. The postulates of Carvalho (1984) and Brait (1982) was used for the Guimarães Rosa literature.
\end{abstract}

KEYWORDS: Lexicon; Neology; Guimarães Rosa.

\section{REFERÊNCIAS}

ALVES, Ieda Maria. A integração dos neologismos por empréstimo ao léxico português. Alfa: Revista de Linguística, São Paulo: UNESP, v. 28, n. Supl, p. 119-126, 1984.

. O conceito de neologia: da descrição lexical à planificação lingüística. Alfa: Revista de Linguística, São Paulo: UNESP, v. 40, p. 11-16, 1996.

. Neologismo: criação lexical. São Paulo: Ática, 2004.

. Neologia e níveis de análise linguística. In: ISQUERDO, Aparecida Negri; ALVES; Ieda Maria (Orgs.). As ciências do léxico - lexicologia, lexicografia, terminologia. Campo Grande, MS: Ed. UFMS; São Paulo: Humanitas, 2007. p. 77-91.

AZEVEDO, Felipe Campos de. A autoridade clássica em "Fatalidade" de Guimarães Rosa. Cadernos de Letras, Niterói: UFF, v. 28, n. 56, p. 371-389, 2018.

BASÍLIO, Margarida. Formação e classes de palavras no português do Brasil. 3. ed. São Paulo: Contexto, 2011.

BRAIT, Beth. Guimarães Rosa: literatura comentada. São Paulo: Abril Cultural, 1982. 
CARDOSO, Elis de Almeida. A criação neológica estilística. Matraga, Rio de Janeiro: UERJ, v. 16, p. 105-118, 2004.

. A poesia: escolha lexical e expressividade. In: GIL, Beatriz Daruj; CARDOSO, Elis de Almeida; CONDÉ, Valéria Gil. Modelos de análise linguística. São Paulo: Contexto: 2009. p. 67-77.

CARDOSO, Elis de Almeida; IGNEZ, Alessandra Ferreira. A interpretação dos neologismos literários: uma forma de entender o texto. In: I Simpósio Mundial de Estudos de Língua Portuguesa - SIMELP, 1., 2008, Anais do I Simpósio Mundial de Estudos de Lingua Portuguesa, São Paulo: FFLCH-USP, 2008. Disponível em: http://simelp. fflch.usp. br/sites/simelp. fflch.usp. br/files/inline-files/S2404.pdf. Acesso em: 08 abr. 2014. s/p.

CARVALHO, Nelly. O que é neologismo. São Paulo: Brasiliense, 1984.

CAVALCANTE, Francisco Tarcísio. A produtividade lexical do sufixo -mente na língua portuguesa. Revista de Letras, Fortaleza: UFC, n. 2, v. 18, p. 54-62, 1996.

FERRAZ, Aderlande Pereira. Neologismos na publicidade impressa: processos mais frequentes no português do Brasil. In: ISQUERDO, Aparecida Negri; ALVES; Ieda Maria (Orgs.). As ciências do léxico - lexicologia, lexicografia, terminologia. Campo Grande, MS: Ed. UFMS; São Paulo: Humanitas, 2007. p. 53-64.

FERREIRA, Aurélio Buarque de Holanda. Novo dicionário Aurélio da Lingua Portuguesa. 2. ed. Rio de Janeiro: Nova Fronteira, 1986.

HOUAISS, Antonio; VILLAR, Mauro de Salles; FRANCO, Francisco Manoel de Mello. Dicionário Houaiss da língua portuguesa. Rio de Janeiro: Editora Objetiva, 2001.

IGNEZ, Alessandra Ferreira. O romance: a formação neológica de adjetivos. In: GIL, Beatriz Daruj; CARDOSO, Elis de Almeida; CONDÉ, Valéria Gil. Modelos de análise linguística. São Paulo: Contexto, 2009. p. 29-45.

KEHDI, Valter. Formação de palavras em português. São Paulo: Ática, 1992. . Morfemas do português. São Paulo: Ática, 1999.

MARTINS, Evandro Silva. O neologismo cruzesouziano e o simbolismo. In: ISQUERDO, Aparecida Negri; ALVES; Ieda Maria (Orgs.). As ciências do léxico - lexicologia, lexicografia, terminologia. Campo Grande, MS: Ed. UFMS; São Paulo: Humanitas, 2007. p. 65-75.

MARTINS, Nilce Sant'Anna. O Léxico de Guimarães Rosa. 2. ed. São Paulo: EDUSP, 2001.

ROCHA, Luiz Carlos de Assis. Estruturas morfológicas do português. Belo Horizonte: Ed. UFMG, 1998.

ROSA, João Guimarães. Primeiras estórias. Rio de Janeiro: Nova Fronteira, 2001. 
SANDMANN, Antônio José. Novidades do "FRONT" da formação de palavras. Revista Letras, Curitiba: UFPR, v. 36, p. 54-68, 1987.

SILVA, Maria Cecília P. de Souza-e-; KOCH, Ingedore Villaça. Linguistica aplicada ao português: morfologia. 18. ed. São Paulo: Cortez, 2011.

SUASSUNA, Lívia. Arcaísmos em Guimarães Rosa. Filologia e Lingüistica Portuguesa, São Paulo: USP, n. 3, p. 65-88, 1999.

WEISZFLÖG, Walter. Michaelis: Moderno Dicionário da Língua Portuguesa. São Paulo: Companhia Melhoramentos, 1998.

Recebido em: 23/04/2019. Aprovado em: 11/07/2019. 